\title{
Investment in Hydrogen Engine Must Be Ended with Failure
}

\author{
Tianquan Yun \\ School of Civil Engineering and Transportation, South China University of Technology, Guangzhou, China \\ Email: cttqyun@scut.edu.cn
}

Received 26 September 2015; accepted 16 February 2016; published 19 February 2016

Copyright (C) 2016 by author and Scientific Research Publishing Inc.

This work is licensed under the Creative Commons Attribution International License (CC BY). http://creativecommons.org/licenses/by/4.0/

c) (i) Open Access

\begin{abstract}
This paper studies the practicable of hydrogen as a renewable energy source. The study proves a theorem on indirect energy conversion, suggests a monetary unit measured by unit energy, in which, comparing values of different industrial products and comparing different techniques used in production of the same product are better than that of money measured by gold, and proves an assertion, in which, the energy by decomposing a unit water is greater than that by composing a unit water, based on the law of conservation energy. According to the above, we get a conclusion: investment in hydrogen engine must be ended with failure.
\end{abstract}

\section{Keywords}

Hydrogen Engine, Law of Conservation Energy, Indirect Energy Conversion, Money Measured by Energy

\section{Introduction}

In seeking new renewable energy source, hydrogen brings rich imagine to people. Hydrogen might be a hopeful potential energy source, because it can be obtained from water decomposition and hydrogen engine does not release pollutants. Therefore, the "hydrogen economy" [1] (including hydrogen production [2] [3], storage [4]-[6], delivery (transmission), hydrogen safety, hydrogen engine [7], and costs [8], etc.) is developing to a world-scale. A lot of information on hydrogen economy can be found in internet and shows that the scale of hydrogen economy is huge. For example, a report on estimation of China's hydrogen engine industry and strategy of future investment in 2014-2019 [9]; The H2USA project [10], etc.

However, is such huge-scale investment in hydrogen economy valuable?

Many sources can also be environmentally clean, e.g., solar energy, wind energy, electric energy, etc. As indicated by U.S. Department of Energy: "The over challenge to production hydrogen is costs" [10], cost is the 
key of the winner in competition among hydrogen engine and electrical driven devise etc.

As an example of the application of the author's papers [11] [12], this short study asserts that investment in hydrogen engine must be ended with failure, based on law of conservation energy. The costs of hydrogen engine (where the hydrogen is produced by decomposition from water using electricity; hydrogen produced by fossil fuels is not renewable, and is not considered here), must be greater than that by electric driven devise.

Section 2 proves an assertion on energy, in which, based on the law of conservation energy, energy by decomposing a unit water is greater than that by composing a unit water. In Section 3, for accuracy to compare the costs of various techniques, ruling out non-technical factors, such as financial aid, and tax-free, a monetary unit measured by unit energy is suggested. In Section 4, a theorem on indirect energy conversion is proved. According to this theorem, and the money measured by energy, the cost of electrical engine (directly translating electrical energy to mechanical energy) is lesser than that of hydrogen engine (indirect energy conversion, i.e., firstly hydrogen production is needed, in which electrical energy is conversed to produce hydrogen. Secondary, the hydrogen energy is conversed to mechanical energy to drive vehicles by hydrogen engine). Finally, a conclusion is summarized.

\section{Assertion}

ASSERTION: Energy by decomposing a unit water is greater than that by composing a unit water. In the following, $A:=B$ means that $A$ is defined by $B$.

\section{PROOF OF THE ASSERT}

$$
E_{1}:=\min _{\forall T}\left\{E \mid T: 2 \mathrm{H}_{2} \mathrm{O} \rightarrow 2 \mathrm{H}_{2}+\mathrm{O}_{2}\right\},
$$

where $E_{1}$ is the minimum energy of production a unit $\mathrm{H}_{2}$ of all kinds of techniques $T$.

$$
E_{2}:=\max _{\forall H}\left\{E \mid H: 2 \mathrm{H}_{2}+\mathrm{O}_{2} \rightarrow 2 \mathrm{H}_{2} \mathrm{O}\right\},
$$

where $E_{2}$ is the maximum energy of emission from hydrogen engines of all kinds of techniques $H$.

Note that $E_{1}$ and $E_{2}$ are obtained by ideal techniques. The costs of energy $E_{p 1}$ of any practical technique to produce a unit $\mathrm{H}_{2}$ is greater than $E_{1}$, i.e., $E_{p 1}>E_{1}$. Similarly, $E_{p 2}<E_{2}$, where $E_{p 2}$ is the obtained energy from any practical technique of hydrogen engine.

Now, there are only three possibilities:

$$
\begin{aligned}
& \text { 1) } \Delta E=E_{2}-E_{1}>0 \text {, } \\
& \text { 2) } \Delta E=E_{2}-E_{1}=0 \text {, } \\
& \text { 3) } \Delta E=E_{2}-E_{1}<0 \text {. }
\end{aligned}
$$

Case 1:

Suppose that Equation (3) holds, then, one can get more and more energy from the circling of getting hydrogen from water by $E_{2}$ and getting water from hydrogen engine by $E_{1}$, so that a perpetual motion machine forms, which is impossible, since it violates the law of conservation energy.

Case 2:

In fact, Equation (4) shows that

$$
\Delta E_{p}=E_{p 2}-E_{p 1}<E_{2}-E_{1}<0,
$$

where subscript $p$ indicates practical case.

Both case 2 and case 3 mean that the energy of getting hydrogen from decomposition of water is greater than that energy emission from hydrogen engine by composition the same water in practice.

\section{Money Measured by Energy}

In order to judge a technique is success or failure, a monetary unit measured by unit energy (ruling out the effects of financial aid and tax-free from government, etc.) is suggested.

To produce industrial product needs spending energy. The relationship between industrial products and its spending energy is obviously closer than that with spending gold. Therefore, the application of money measured by energy is better than that money measured by gold for discovery of relation between values of different in- 
dustrial produces, and for comparing techniques used in the same industrial product.

Let the monetary unit is measured by unit energy, i.e.,

$$
M=E \text {. }
$$

Similarly,

$$
\begin{gathered}
M_{1}=E_{1}, \\
M_{2}=E_{2}, \\
M_{p 1}>M_{1}, \\
M_{p 2}<M_{2},
\end{gathered}
$$

where $M_{1}$ is an ideal (theoretical) money to create a unit $\mathrm{H}_{2}$ by ideal method from water; $M_{2}$ is an ideal money obtained from ideal hydrogen engine using a unit $\mathrm{H}_{2} ; M_{p 1}$ is the money to create a unit $\mathrm{H}_{2}$ from water by a practical method; $M_{p 2}$ is the money obtained from a practical hydrogen engine burning a unit $\mathrm{H}_{2}$.

By (6), we have

$$
\Delta M_{p}=M_{p 2}-M_{p 1}<0 .
$$

Equation (12) shows that the money creating by any practical technique of hydrogen engine using $\mathrm{H}_{2}$ from water is less than the money costs on production $\mathrm{H}_{2}$ from water.

If the costs of storage, transportation and safety are taken into account, then Equation (12) becomes to

$$
M_{p 2}<M_{p 1}+M_{p 3}+M_{p 4}+M_{p 5},
$$

where $M_{p 3}, M_{p 4}$ and $M_{p 5}$ are the costs of storage, transportation and safety of a practical technique for a unit $\mathrm{H}_{2}$ respectively.

Obviously, Equation (13) shows that the money creating by hydrogen engine using $\mathrm{H}_{2}$ from water is much less than the money costs on production, storage, transportation and safety of $\mathrm{H}_{2}$.

\section{Theorem of Indirect Energy Conversion}

In the following, the path of energy $E_{A}$ converted into energy $E_{C}$ directly is called "direct conversion", while the path from energy $E_{A}$ converted to energy $E_{B}$ and from $E_{B}$ converted to energy $E_{C}$ is called "indirect conversion" or "multi-conversions".

Theorem: In energy conversion, the loss of energy of the indirect method is bigger than that by direct method.

Proof:

Suppose that the losses of energy in energy $E_{A}$ converted into energy $E_{c}$ and $E_{B}$ are $L_{A C}$ and $L_{A B}$ respectively. i.e.,

$$
\begin{aligned}
& L_{A C}=E_{A}-E_{C}, \\
& L_{A B}=E_{A}-E_{B} .
\end{aligned}
$$

Similarly, the loss $L_{B C}$ of energy in $E_{B}$ converted to $E_{C}$ is

$$
L_{B C}=E_{B}-E_{C} .
$$

Now, for an indirect conversion, we have

$$
L_{A C}=L_{A B}+L_{B C} .
$$

In practice, the losses are greater for practical cases than that of the ideal cases, i.e.,

$$
\begin{aligned}
& L_{p A C}>L_{A C}, \\
& L_{p A B}>L_{A B}, \\
& L_{p B C}>L_{B C} .
\end{aligned}
$$

There are so much people engaging in works of various methods. They do the best to minimum the loss in 
energy conversion. For a fair estimation, suppose that the same loss percentage, in future is $30 \%$ in each conversion. Then, we have from Equations (17)-(20):

$$
\begin{gathered}
L_{A C}=0.7 L_{p A C}, \\
L_{A B}=0.7 L_{p A B}, \\
L_{B C}=0.7\left(0.7 L_{p B C}\right) .
\end{gathered}
$$

Equation (23) shows the twice conversions, each has $30 \%$ of energy loss. So that we have

$$
L_{p A C}<L_{p A B}+L_{p B C} \text {. }
$$

Equation (24) shows that the energy loss for direct conversion is less than that of indirect (multiple conversion) conversions.

Application of this theorem, the loss of energy of electrical energy $E_{A}$ directly converting to mechanical energy $E_{C}$ to drive a car is smaller than that of indirect conversions from $E_{A}$ to $E_{B}$ and from $E_{B}$ to $E_{C}$ by hydrogen engine.

A recently example of an aero-plane made by Airbus company driving by electrical engine across English bay is reported on 2015-07-12 [13]. Which shows that the future of application of electrical engine to cars or plane with no air-pollutants is bright.

\section{Conclusion}

According to the theorem, the suggested monetary and the assertion, investment in hydrogen engine must be ended with failure. If any technique exists relying on financial aid and tax-free from government, then it can't last. Finally it must be ended with failure. Like the famous words of Engels: "despise on dialectics is foredoomed to be punished." To despise on the law of conservation of energy is also foredoomed to be punished.

\section{References}

[1] (2014) www.wikipedia.com/English/hydrogeneconomy

[2] Carmo, M., Fritz, D., Merjel, J. and Storlten, D. (2013) A Comprehensive Review on PEM Water Electrolysis. Journal of Hydrogen Energy, 38, 4901-4934. http://dx.doi.org/10.1016/j.ijhydene.2013.01.151

[3] (2001) High Pressure Electrolysis. The Key Technology for Efficient H.2.

[4] A Portfolio of Power-Trains for Europe: A Fact Base Analysis.

[5] (2006) BMW Group Clean Energy ZEV Symposium. 12.

[6] Eberle, U. and von Helmolt, R. (2011) Sustainable Transportation Based on Electric Vehicle Concepts: A Brief Overview. Energy \& Environmental Science, Royal Society of Chemistry, 14 May 2010.

[7] National Academy of Engineering (2004) The Hydrogen Economy: Opportunities, Costs, Barriers, and R\&D Needs. The National Academic Press, Washington DC.

[8] (2005) DOI Announces New Hydrogen Costs Goal. US. DOE.

[9] (2014) www.zyzyiy.com/baogao

[10] (2015) http://www.nanowerk.com/news2/green/newsid\%3D35448.php

[11] Yun, T.Q. (2014) Criteria of True and Its Applications. European International Journal of Science and Technology, 3, 45-48.

[12] Yun, T.Q. (2015) A Method for Seeking Range of Missing Plane Based on Law of Energy Conservation. British Journal of Science and Technology, 9, 206-211. http://dx.doi.org/10.9734/BJAST/2015/16660

[13] (2015) http://www.indiatvnews.com/news/world/airbus-electric-plane-to-fly-across-English-channel.html 